\title{
PSICANÁLISE: A CLÍNICA E O PROJETO TRANSFERENCIAL
}

\author{
Gustavo Adolfo Ramos Mello Neto
}

\begin{abstract}
RESUMO. O autor objetiva propor algumas considerações sobre o processo psicanalítico, sobretudo no que se refere a como ele começa e quais são as suas condições para começar. Examinando o texto freudiano, mais especificamente os denominados textos técnicos de 1914, sugere que esse processo começa por uma relação de sedução inconsciente vinda do analista/terapeuta e, mesmo, da própria situação analítica. Do lado do paciente, por sua vez, o autor propõe a ideia de um projeto transferencial, algo construído pelo paciente, composto de fantasmas, de um lado, e de representações-meta conscientes, de outro, no qual o analista tem designado um lugar. Se o analista recusa-se a participar desse projeto, a análise/psicoterapia não se inicia de fato.
\end{abstract}

Palavras-chave: Psicanálise; transferência; processo analítico.

\section{PSYCHOANALYSIS: PRACTICE AND THE TRANSFERENCE PROJECT}

\begin{abstract}
The author aims to propose some considerations on the psychoanalytical process, particularly with regard to the start of the process and its conditions for starting. By examining Freudian texts - specifically the so-called 1914 technical papers - he suggests that this process begins with a non-conscious seductive relationship started by the analyst/therapist, and even from the analytical situation itself. On the part of the patient, the author proposes the idea of a transference project, something constructed by the patient, consisting of specters on one hand, and by purposive ideas on the other, wherein the analyst/therapist has a designated role. If the analyst/therapist refuses to participate in the project, analysis/psychotherapy does not truly begin.
\end{abstract}

Key words: Psychoanalysis; transference; analytical process.

\section{PSICOANÁLISIS: LA CLÍNICA Y EL PROYECTO TRANSFERENCIAL}

RESUMEN. El autor propone algunas consideraciones sobre el proceso psicoanalítico, sobretodo en relación a como empieza y cuales son sus condiciones para empezar. Examinando el texto freudiano, más precisamente los llamados textos técnicos de 1914, sugiere que esse proceso comienza por una relación de seducción inconsciente, que viene del analista/terapeuta y aun de la propia situación analítica. De la parte del paciente, por sun lado, el autor plantea la idea de un proyecto transferencial, algo construido por el paciente, compuesto, por un lado, por fantasmas, y, por otro, por representaciones-meta conscientes, en lo cual el analista tiene un lugar desinado. Si el analista se recusa a participar de esse proyecto, el análisis/psicoteria no comienza de hecho..

Palabras-clave: Psicoanálisis; transferência; processo analítico.

\footnotetext{
Doutor em Psicologia Escolar e do Desenvolvimento Humano, USP. Pós-doutorado em Psicanálise e Psicopatologia Fundamental, Université de Paris VII, Professor Associado C, UEM, Paraná, Brasil.
} 
O propósito deste texto se refere a tentar responder à questão "o que faz um psicanalista?", que nos foi colocada num certo evento, mas que, para além deste, nos aparece a proposta desde sempre em nosso trabalho. Este artigo tem, então, a finalidade de sistematizar uma prática, sugerindo esta sistematização para outros. Vamos, pois, usar o texto freudiano como apoio para nossos comentários e, finalmente, introduzimos nossa proposta (que não exclui aquilo que interpretamos em Freud).

A frase interrogativa "O que faz um psicanalista?" tal como ela está construída, tem pelo menos dois sentidos. Um primeiro, mais óbvio, se refere a algo instrumental, em que o analista é o sujeito do verbo fazer, ele faz algo, constrói, destrói, propicia, deixa que ocorra etc. $\mathrm{O}$ outro sentido é aquele em que o substantivo "analista" faz parte do predicado da frase, isto é, ele é feito e o que se quer saber com essa questão é, sobretudo, como ele se torna analista.

Ora, essas duas faces da pergunta se cruzam em algum ponto, mas aqui, pelo menos a princípio, vamos nos debruçar apenas sobre o primeiro sentido, o mais óbvio e instrumental. Comecemos com Freud, como uma base necessária à nossa construção e comecemos com o Freud dos anos 1890, que é ainda muito ingênuo, mas muito criativo. Antes de fazê-lo, contudo, é preciso fazer um parêntese e dizer que o presente trabalho se inspira na Teoria da Sedução Generalizada, sobretudo nas ideias de Laplanche (1992) sobre a transferência enquanto provocação do analista. Trata-se apenas de uma inspiração, uma inspiração distante e não de um enquadramento e é por isso que o leitor não encontrará nenhuma dissertação direta sobre os conceitos laplanchianos. Dito isso, vamos, pois, a Freud sem mais delongas.

\section{EM FREUD}

Na década de 1890, momento, que se pode considerar brilhante para a humanidade em termos de criações teóricas, Freud está às voltas tanto com os problemas da teoria, quanto com os da técnica. Sabemos que ambas vão sofrer uma verdadeira revolução no fim dessa década, que é também o apagar das luzes do século XIX. Mesmo assim, algo seja da técnica, seja da teoria produzida nesse início de teorizar, que alguns denominam de pré-psicanalítico, permanece e está presente até os nossos dias.

Em Estudos sobre a histeria (Freud, 1895/1990), mais precisamente no capítulo intitulado "A psicoterapia da histeria", Freud descreve a maneira como utilizava o método catártico, principalmente quando se trata de pacientes não-hipnotizáveis. Ao fazê-lo, introduz, pois, o que conhecemos hoje como regra fundamental. Conta-nos que dizia para o paciente que lhe faria uma pressão na testa e que, então, viriam à sua mente recordações na forma de imagens. Pedia ao sujeito que lhe comunicasse tais recordações fossem quais fossem:

\begin{abstract}
Digo-lhe que não lhe é permitido dizer que não pode opinar, que [a recordação] não é, por acaso, a procurada, a pertinente ou porque é desagradável dizer. Nada de crítica, nem de reserva, provenham elas do afeto ou do menosprezo. Afirmo-lhe que só assim poderemos encontrar o procurado e que assim infalivelmente o acharemos. Em seguida, pressiono a testa do enfermo (...) (Freud, 1895/1990, p. 277).
\end{abstract}

É bem verdade que a técnica se modifica e que a pressão na testa, o questionário sobre a recordação e, mesmo, a hipnose, quando havia, foram substituídos pela livre associação. Mesmo assim, a transmissão da regra ao paciente se manteve. Desse modo, temos, então, uma primeira coisa que faz um psicanalista: antes de tudo ele assegura regra fundamental, sendo seu guardião, e é ela que inaugura a situação analítica.

Além disso, Freud (1895/1990) relata também que seu método exige muito do terapeuta. Trata-se de um processo penoso para ele e que exige interesse por parte do paciente.

Esse aspecto penoso da técnica ganha uma interpretação metapsicológica por meio da ideia de resistência, que é interpretada aí e subsequentemente como um braço do recalque. Trata-se da dinâmica, isto é, do conflito de forças. Mas, é interessante que a medida desse conflito é o homem, é o analista. Freud (1895/1990) diz-nos, então, que a resistência do paciente é equivalente da pressão, pressão psicológica, que o analista faz sobre ele e sobre o material recalcado. Essa ideia é interessante porque se trata de uma implicação, (embora Freud nunca tenha dado grande importância a ela). Isto é, algo que faz também o analista é estar implicado, sentindo penosamente à resistência do paciente.

A implicação, no método catártico, é, sobretudo, ativa. $\mathrm{O}$ analista pressiona, exige, exalta e, mesmo, admoesta. Isso parece muito distante do método psicanalítico propriamente, em relação ao qual se diz que o analista tem um papel mais passivo - de tão passivo pode até ser morto. Do outro lado, no método catártico, está o paciente e seu papel que, quando comparado ao terapeuta, é passivo, embora a resistência se mostre bem ativa. No método psicanalítico seria o contrário, o paciente é que colocaria o analista em vários lugares de seu fantasma, de acordo com os momentos de sua análise. 
A implicação pessoal do terapeuta catártico é magnificamente descrita neste trecho:

\begin{abstract}
Agimos o melhor que podemos na qualidade de esclarecedores, se a ignorância produziu medo; de mestres, de expoentes de uma concepção universal mais livre e superior; de confessores, que ministram a absolvição mediante $\mathrm{o}$ interesse que não cessa e o respeito que não fraqueja em consequência da confissão. Tentamos enfim ajudar humanamente ao paciente até onde o consentem o alcance de nossa própria personalidade e o grau de simpatia que possa brindar o caso em questão (Freud, $1895 / 1990$, p. 288).
\end{abstract}

A ideia aí é a de minimizar a resistência, já que é suposto que ela se apoia em alguma espécie de visão de mundo menos tolerante. Não cremos que, com a criação do método propriamente psicanalítico, essa postura tenha se modificado.

Ao encerrar o capítulo, que é o último, Freud (1895/1990) fala da transferência, justamente com essa palavra. Trata-se, nesse momento da teorização, de explicá-la, a transferência, como um falso enlace. Relata, então, o caso de uma paciente cujo sintoma era atribuído ao desejo, numa certa ocasião, de que o homem com quem conversava a beijasse. Esse desejo teria se estendido à análise e, num certo momento, a paciente teria tido o desejo, talvez consciente, de que Freud a beijasse. Frente a tal sentimento, a senhora apavorara-se e somente voltou a entregar-se ao tratamento quando Freud descobriu e verbalizou esse desejo.

Pois bem, seja enquanto confessor ou portador de uma visão de mundo mais tolerante, seja como objeto de transferência, o analista se oferece ao analisando, se oferece como objeto, um objeto mais apetecível, isto é, como objeto sedutor e a ser seduzido e aí está mais algo que faz o analista. Ao ser o representante de uma concepção humana mais tolerante, está de algum modo permitindo ou, ainda, dizendo de maneira sutil que aquilo que não pode, pode. Essa visão de mundo supostamente mais tolerante funciona, pois, como uma espécie de armadilha. $\mathrm{O}$ que Freud ainda não sabia é que, para além disso, bastava sua simples presença, ela em si já era um oferecimento amoroso.

Mas, façamos, agora, um salto cronológico; vamos aos anos 1913-1915, aos denominados artigos técnicos de Freud, e, seguindo em ordem cronológica, encontramos "A dinâmica da transferência" (Freud, 1912/1990). A proposta aí é de mostrar que a transferência se produz necessariamente na análise e se desenvolve a partir de vários fatores. Um desses é a insatisfação, isto é uma parte das moções pulsionais mantém-se longe da consciência, como se escondendo aí, como as crianças se escondem nos cantinhos, digamos, e só se manifesta nas fantasias, pois não encontra saída na realidade material. Está, portanto, insatisfeita e o sujeito está insatisfeito e é "normal", então, que ele tome o analista como objeto para a contenção dessa insatisfação libidinal. Ora, Freud sabe disso bem antes que o paciente o procure, mas, vejamos que, mesmo sabendo, ele se coloca nesse lugar. Esse saber antecipado é, talvez, um sinal de que não se trata, da parte do analista, de inteira passividade. Colocar-se no lugar do desejo do outro não tem necessariamente nada de passividade, mas de provocação e eis aí outra coisa que o analista faz: provocar. Aliás, é justamente assim que age o sedutor, descobre o desejo do outro e coloca-se aí como objeto.

Freud (1912/1990) supõe que há um engano de objeto, que não é a ele que se dirige de fato esse desejo, mas a algo ou alguém outro que pode ser figurado num atrás ou num além do analista. Além disso, ele não se engana, pois sabe que colocado nesse lugar, nesse campo transferencial, que é um campo de sedução, está pisando em uma armadilha: a transferência é resistência. Aos poucos, esse campo vai se tornar o palco de todos os conflitos. Entenda-se aí palco como metáfora militar: o palco das operações, operações de combate. Os conflitos de que fala Freud são, sobretudo, os conflitos infantis do sujeito, conflitos entre a pulsão e a defesa, mas não só isso, há conflito entre analista e analisando, no sentido de que um busca manter a resistência e o outro busca, digamos, convencer o segundo de que abandonar a resistência não é tão insuportável assim. E aí está outra coisa que faz o analista: combater. Mas não se trata de um combate qualquer, mas de um combate amoroso em muitos sentidos. A eventual confissão de amor da paciente ou do paciente e a tentativa de sua realização, diz Freud (1912/1990), tem a finalidade de produzir um impasse e, sendo assim, é claramente um fruto da resistência e, logo, do recalcamento. Mas, vejamos que se trata também de um ato óbvio de sedução e aí está a armadilha: seduzir para paralisar.

Na sequência, Freud (1912/1990) nos anuncia a solução que vê não como ideal, mas como necessária em relação a esse combate transferencial. Trata-se da interpretação e isso tem a ver com dizer para o paciente, seja de que modo for, que suas tentativas amorosas têm a ver com a resistência e, por vezes, que há um desvio de objeto. Trata-se, então, de desmascarar e aí está outra coisa que faz o analista, desmascara o paciente na sua tentativa de levar a análise para um beco sem saída. Portanto, o analista é alguém que se coloca no lugar do objeto, seduz, tornase, assim, objeto de sedução e, quando isso chega a certo ponto, denuncia toda a situação. Quando, pois, a 
resistência/sedução é denunciada, diz Freud, descolam-se da figura do analista seus elementos inconscientes (da transferência) e o que fica, mesmo seja por pouco tempo, é uma transferência suportável, digamos, um bem querer ou, mesmo, uma certa irritação. A proposta, então, é de aproveitar o estado transferencial que aí se produz, digamos, para continuar com o tratamento, mas denunciando esse mesmo estado em certos momentos.

Eis um trecho que resume tudo isso:

As moções inconscientes não querem ser recordadas (...), mas aspiram a reproduzir-se em consonância com a temporalidade e a capacidade de alucinação do inconsciente (...). O médico quer fazê-lo inserir essas moções de sentimento na trama do tratamento e de sua biografia [através da interpretação] (...). Essa luta entre médico e paciente, entre intelecto e vida pulsional, entre discernir e querer "atuar" se desenvolve quase exclusivamente em termos transferenciais. É nesse campo em que se deve obter vitória, cuja expressão será sanar duradouramente a neurose [o que é bastante questionável]. (Freud, 1912/1990, p. 105)

E sobre o envolvimento do analista:

É inegável que dominar os fenômenos da transferência faz o analista deparar-se com as maiores dificuldades, mas não se deve esquecer que justamente eles bridam o inestimável serviço de tornar atuais e manifestas as moções de amor escondidas e esquecidas pelos pacientes; pois, em definitivo, ninguém pode aplicar justiça in absentia ou in effigie. (Freud, 1912/1990, p. 105).

Nessa última frase, é preciso que o paciente viva a transferência, mas podemos interpretar que é preciso que ambos, paciente e analista, a vivam, já que o analista tem "que se deparar com as maiores dificuldades" (Freud, 1912/1990, p. 105). No entanto, vê-se que, a implicação do analista é aí bastante restrita, não é mais que um incômodo, seguido de um esforço para suportar o que vem do paciente.

Outro texto, "Apontamentos sobre o amor de transferência", de 1915, Freud (1915/1990) vai tomar de forma mais evidente essa problemática do amor (e da sedução, digamos nós). A ideia é discutir a técnica e a transferência pelas observações acerca de casos em que a paciente se apaixona claramente pelo analista.

O analista, diz Freud (1915/1990), tem que ser ou tornar-se, digamos - diferente do leigo. Ele tem que ter para si que não se trata de um amor por ele propriamente, mas um produto da situação analítica.
Ou seja, Freud reconhece, de algum modo, o que há de provocativo na análise e no analista, que é seu guardião.

A paciente, por sua vez, não terá outra saída a não ser aceitar que esse enamoramento é parte constitutiva de sua análise. Trata-se, diz-nos ainda Freud (1915/1990), de um enamoramento que já existia desde o começo, mas que se torna visível a partir do surgimento de fortes resistências. Com isso, a paciente como que rebaixa o analista que agora é o amado, isto é, alguém muito próximo e tangível.

Prossegue Freud (1915/1990), sobretudo quando iniciante, o analista vê-se um tanto perdido numa situação como essa. Ele tem como saída, por exemplo, reprovar a paciente, estimulando-a a que controle semelhantes impulsos. Essa é uma saída moralizante, mas, no lugar do moralizante, ele propõe a técnica, o terceiro ${ }^{1}$, a Lei, pois, levar a paciente a conter esses sentimentos não seria algo psicanalítico, mas seria a sufocação do próprio pulsional. Seria como, diz Freud: “(...) fazer subir um espírito do mundo subterrâneo, conjurando-o engenhosamente, para, então, enviá-lo de volta para baixo sem perguntar-lhe nada. Ter-se-ia chamado o reprimido à consciência só para reprimi-lo de novo, presa de terror". (Freud, 1915/1990, p. 167).

Não cremos ser sem importância reiterar que aí se trata também de provocação: desafiar os espíritos e depois dispensá-los sumariamente. O que Freud recomenda é o que denomina indiferença e, ao lado disso, a abstinência.

Esse enamoramento, diz, não é mais que repetição de reações anteriores e, muitas dessas, infantis. No entanto, esse argumento leva ao impasse e o próprio Freud (1915/1990) o aponta: todo enamoramento repete modelos infantis. Desse modo, o amor de transferência é também um amor genuíno, uma vez que todo amor é um engano de objeto, digamos, e sua forma tão exagerada teria como causa a resistência e a própria situação analítica.

Mas, ao analista não é dado ceder às demandas da paciente. Paciente e analista têm que, juntos, "aprender a vencer o princípio do prazer" (Freud, 1915/1990, p. 173). A partir daí, podem ambos se elevar a um plus de liberdade psíquica, que viria não só da abstinência pulsional, mas também da análise do inconsciente que isso permitiria. Não é muito difícil

\footnotetext{
Laplanche (1993), em A tina, diz algo interessante a esse respeito. Ao comentar as sessões de tempo variável, praticadas pelos lacanianos, se pergunta sobre como ter garantias de que a interrupção ou corte de uma sessão não teria sido obra de algo inconsciente do analista e não se tratou de uma medida arbitrária. A resposta que dá é que mais vale aí inserir a Lei, o terceiro, que nesse caso seriam as sessões de tempo fixo, acordadas em contrato com o paciente e que ambos, analista e paciente devem respeitar.
} 
ver aí um discurso estoico, no sentido de que o estoico faz do autocontrole, da calma e da indiferença um caminho para a liberdade e para a verdade (Ferrater Mora, 1956). Eis, então, mais algo que faz o psicanalista: coloca-se numa posição estoica. Portanto, o analista provoca, seduz e, então, mantém-se numa posição estoica, convidando o paciente a também fazêlo.

Manter essa postura estoica é, pois, uma espécie de luta. Vejamos este trecho:

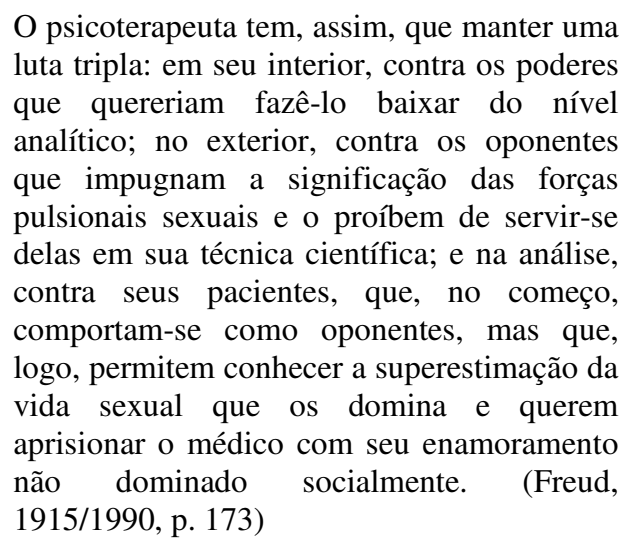

Concluindo o texto, Freud (1915/1990) traz outra metáfora, a do químico: "o psicanalista trabalha com forças mais explosivas e lhe fazem falta a mesma cautela e escrupulosidade do químico" (p. 173).

Podemos unir essa metáfora à do feiticeiro ou do aprendiz de feiticeiro, que se vê diante de forças que não pode dominar. Nesse sentido, o analista é aquele que, juntamente com o analisando, vai fazer algo que disparará um processo que é impossível saber que rumo tomará. O analista é, então, um feiticeiro, quase aprendiz, que provoca um processo e o faz pela sedução e, em seguida, porta-se estoicamente frente a suas consequências. Esse portar-se estoicamente não se refere apenas a suportar, mas também a interpretar, pois este é um substituto do agir. Frente às forças pulsionais, o analista, tal como Freud o percebe, lança mão da ciência, da sua ciência, no sentido mais antigo, que é o de sabedoria. Isso também é algo que faz o psicanalista: ciência. E o faz tanto no sentido do seu trabalho, como de sua formação. Ele busca dominar as próprias forças que convocou intervindo sabiamente sobre elas. Busca anular algumas delas, re-encaminhar outras, e mais frequentemente se limita a apenas interpretar, nos vários sentidos que isso tem, acreditando que o melhor acontecerá; isto é, que levado sob interpretação, esse processo terá como destino a liberdade do sujeito. Ele ficará menos submetido aos seus processos inconscientes já que agora não somente os liberou, como os conheceu.
Pois bem, do ponto de vista da formação, pode-se pensar que ela deve ou pode se pautar pelo preparo do analista para que ele saiba colocar-se nesse lugar, que é o da relação da ciência com as forças convocadas pela da provocação, e sustentar-se aí até o fim (ou, ao menos, muitas vezes) de maneira estoica. Essa formação exige saber, pois se trata de ciência, mas também exige algo semelhante ao estoicismo, que é uma experiência de imersão profunda de si mesmo, de todo o seu ser. Para Freud e seu grupo, essa experiência seria uma análise pessoal do analista que, muitas vezes, era muito rápida, não sendo muito mais que uma demonstração ${ }^{2}-$; hoje, para muitos, é uma formação, que, além da análise, tem alguma coisa de doutrinário e, por vezes, fanático, como eram os próprios estoicos.

Há, no entanto, até aqui, algo que está presente nas propostas freudianas, mas não na intensidade que talvez devesse ou, talvez, na intensidade que tomará depois de Freud e trata-se da presença do analista dentro da análise. $\mathrm{O}$ analista aí se vê ultrapassado por forças que não domina inteiramente, sente-se angustiado e faz o possível para domesticá-las. Porém, o que não está aí, no discurso freudiano, é a possibilidade de uma participação mais efetiva tanto do analista, como do analisando. Isso no sentido de que o analista está mais envolvido enquanto sujeito do que aparece no texto de Freud, assim como o analisando tem uma participação mais ativa na direção da análise.

Façamos, sobre isso, apenas uma pequena observação.

\section{MAIS DO QUE PARECE}

Temos observado, já há algum tempo, que alguns pacientes procuram o trabalho terapêutico com alguma espécie de projeto. Trata-se de algo que não fica muito claro, nem para o terapeuta e nem para o paciente e, quando se tenta explorar, não se chega a muita coisa, ao menos não no início. Damos um exemplo muito frequente: trata-se de quando uma paciente ou um paciente mudam de analista, buscando um novo analista de sexo oposto ao do anterior.

Neste caso e em outros, o paciente não sabe muito dizer por que fez essa espécie de escolha, mas notemos que uma pequena parte dela é consciente: ele ou ela já sabe ao menos o sexo ou gênero do analista que quer e esse não me parece um saber tão pequeno.

\footnotetext{
É possível pensar que a preparação seja, sobretudo, a análise pessoal, mas cremos que isso vai mais longe, talvez seja uma espécie de transferência com a própria psicanálise, ou, mesmo, um mergulho sectário, que não deixa de ser uma espécie de transferência.
} 
Só que com isso, temos muito pouco. Se nem o paciente consegue dizer por que está fazendo tão grande mudança, como o saberemos nós? É possível pensar que a finalidade seja a busca de um gozo, coisa que não descarto de maneira alguma, mas estamos convencidos, sobretudo pela repetição desse fenômeno, de que o paciente tem realmente um projeto e este é parte consciente, parte inconsciente. E, evidentemente, trata-se de um projeto que inclui o analista e o inclui necessariamente. É possível que isso seja algo ligado ao Édipo, num sentido amplo, no sentido usado por Freud (1933/1990), em "A sexualidade feminina". Ele propõe denominarmos de complexo de Édipo a toda relação da criança com os pais e talvez o sujeito busque reconstituí-lo; e no caso da mudança de sexo do analista, re-encene esse Édipo com um analista de cada vez, como se cada uma dessas encenações fosse uma fase de uma única peça. E seja como for, o analista está convidado a desempenhar um papel.

Freud nos diz em seus textos técnicos que o paciente entra em tratamento com muito poucas representações objetivas sobre o que fazer e o que quer. Além da ideia de que espera se curar, não há muito mais que possa aliar-se ao terapeuta em sua árdua tarefa de produzir o inconsciente. Ora, isso continua sendo verdade nos dias de hoje, no entanto, parece que há algo mais.

Um paciente que engendra, por exemplo, uma cena edípica $\mathrm{x}$ ou y para seu tratamento possivelmente já o fez com muitas pessoas no decorrer de sua vida. Quando, então, toma a decisão de levá-la (a cena) para uma análise é porque intui de algum modo que quer resolver o seu enigma e só pode fazê-lo reproduzindoo em laboratório, digamos. Não digo que isso lhe seja claro, mas parece de algum modo estar presente. Desse modo, é possível pensar que a situação analítica, que é única para cada paciente, está fundada não só num projeto racional, mas em elementos inconscientes que fazem parte do projeto. Ela, a situação analítica resultaria, então, de algo muito complexo, difícil de discernir, em que representações conscientes e inconscientes se mesclariam produzindo algo semelhante a um projeto, um projeto transferencial. Esse projeto, pois, teria que se manter durante toda a análise e, ao mesmo tempo, ser interpretado; no entanto, creio que ele só será conhecido inteiramente no après-coup.

Pois bem, e o que faz o analista aí, cede à demanda do paciente? Fábio Herrmann (1991) afirma que o analista, na sua posição de analista não cede ao apelo amoroso do paciente, no entanto, ao falar de sexo com ele, de algum modo está fazendo uma pequena concessão, mas sem que isso comprometa a análise.
Ora, tal ideia é bastante aceitável; a interpretação, ao menos a freudiana, pelo fato de seu objeto ser, sobretudo, sexual tem algo de gozo. Mas, não é só isso, falar de sexo é apenas um incidente, algo menor, digamos. Quando o analista é convocado para ocupar um papel no projeto transferencial do sujeito, não há como não fazê-lo e isso porque é a condição que o paciente está colocando. Agora, quanto a como ocupar é outro problema e isso faz pensar na Gradiva, de Freud (1907/1990), em que Zoe Bertgang aceita o delírio de Hanold, isto é, aceita ser a Gradiva tão procurada em suas fantasias de arqueólogo, mas, ao mesmo tempo, vai insinuando outras coisas, que podem ser entendidas como sutis interpretações. Esse ceder, digamos assim, já está de algum modo em Freud. No entanto, talvez seja preciso pensar que o analista tem que dar mais e é justamente o que faz. Ao aceitar ocupar um lugar no projeto transferencial do paciente, mesmo que com todas as reservas bem conhecidas, ele aceita fazer parte do campo transferencial que está se formando. E é aí que começa a provação dos dois, isto é, o problema de como manter-se aí sem se perder inteiramente e poder sair em algum momento. Alguém tem que fazer algo, digamos. Uma interpretação, um assinalamento ou, mesmo, uma simples exclamação pode ser esse algo num certo momento e fazer algo aí se refere a poder traduzir essa experiência, traduzir, sobretudo, em palavras.

O que queremos dizer são duas coisas. Primeiro, que além de provocar, seduzir e portar-se como que estoicamente, o analista necessita estar dentro do campo transferencial e não fora dele apenas como observador, e isso não encontramos dito em Freud, de forma que o discurso freudiano fica um tanto que excessivamente racional a esse respeito. Segundo, que cremos que o paciente participe mais do que com uma mera e genérica representação de cura. Supomos que, mais que isso, o seu projeto transferencial, por mais primitivo que seja, já é uma tradução daquilo que o move e um dos elementos dessa tradução é a figura do analista, que surge aí como condição para a efetivação desse projeto. A entrada do analista aí não nos parece algo simplesmente passivo, mas é uma participação com sua própria fantasmatização no campo transferencial.

É preciso dizer, ainda, que o projeto transferencial é algo muito vago e não garante nada em relação aos resultados terapêuticos, estes, como se sabe bem, são sempre incertos. Porém, é ele o que sustenta a análise e o que faz um psicanalista, no sentido do que o forma, é a capacidade ou o desenvolvimento da capacidade de poder assumir o seu papel no projeto transferencial, deixar-se usar, e poder, então, metabolizar essa experiência, isto é, traduzi-la em 
palavras, de forma a convidar o paciente a também fazê-lo. Nesse processo, o analista e o paciente possivelmente representam um para o outro, o outro da sedução generalizada e, então, seus discursos são enigmáticos; o analista envia todo o tempo para o analisando frases enigmáticas e o faz propositadamente, e o paciente todo o tempo também está, com sua angústia, dizendo ao analista: decifra-me ou te devoro.

Enfim, retomando tudo que dissemos sobre o que faz o analista, desde a interpretação que fazemos de Freud até o que propusemos enquanto concepção pessoal (uma coisa não exclui a outra), podemos reunir neste conjunto esta estranha sequencia de termos - que não por ser estranha deixa de ser verdadeira - descrevendo o que faz o analista: guarda a regra fundamental e o setting; oferece-se como objeto sedutor e a ser seduzido; provoca; combate (combate amoroso); desmascara; toma uma posição estoica; faz ciência; mas, sobretudo, entra no campo transferencial e no projeto do analisando; traduz, convida a traduzir e aceita ser o outro significativo do paciente, assim como ter de algum modo re-editado o seu próprio outro significativo na figura do paciente. Talvez esse seja o outro da sedução generalizada, aquele cuja mensagem, parasitado por elementos sexuais, foi excessiva para a criança e, para o adulto neurótico tornou-se enigma, que se expressa, por exemplo, em seu sintoma.

\section{REFERÊNCIAS}

Freud, S. (1990). Puntualizaciones sobre el amor de transferência, In J. Strachey (Ed. e José Etcheverry, Trad.). Obras Completas de Sigmund Freud.(Vol. 12, pp. 163-174). Buenos Aires: Amorrortu. Original publicado em 1915).
Freud, S. (1990). Sobre la dinâmica de la transferencia, In J. Strachey (Ed. e José Etcheverry, Trad.). Obras Completas de Sigmund Freud. (Vol. 12, pp. 97-119). Buenos Aires: Amorrortu. (Original publicado em 1912).

Freud, S. (1990). Sobre la sexualidad femenina, In J. Strachey (Ed. e José Etcheverry, trad.). Obras Completas de Sigmund Freud. (Vol. 21, pp. 227-174). Buenos Aires: Amorrortu. (Original publicado em 1933).

Freud, S., \& Breuer, J. (1990). Estudos sobre a histeria. In J. Strachey (Ed. e José Etcheverry, trad.). Obras Completas de Sigmund Freud. (Vol. 2, pp. 1-315). Buenos Aires: Amorrortu. (Original publicado em 1895).

Freud, Sigmund. (1990). El delírio y los sueños en la "Gradiva" de W. Jensen. In J. Strachey (Ed. e José Etcheverry, Trad), Obras Completas de Sigmund Freud. (Vol. 9, pp. 1-80). Buenos Aires: Amorrortu. (Original publicado em 1907).

Herrmann, F. (1991). A clínica psicanalítica: a arte da interpretação. São Paulo: Brasiliense.

Laplanche, Jean. (1992). Du transfert et as provocation par l'analyste. In J. Laplanche. La révolution copernicienne inachevée; travaux 1967-1992 (pp. 417438). Paris: Aubier.

Laplanche, Jean. (1993). A tina - a transcendência da transferência. (Paulo Neves, trad.). São Paulo: Martins Fontes.
Endereço para correspondência:
Gustavo Adolfo Ramos Mello Neto. Rua Professor Ney Marques, 21, CEP 87020-300, Maringá-Pr, Brasil.E-mail: garmneto@gmail.com.
Recebido em 20-07-2012 Aceito em 27-11-2012 